\title{
WASHING-UP AND MOVEMENT OF LITTER ALONG THE FUJI COAST CAPTURED BY LIVE-CAMERA
}

\author{
Masahiro Ito, Department of Environmental Science and Technology, Meijo University \\ maito@meijo-u.ac.jp
}

\begin{abstract}
The total amount of litter washed up along the Japanese coast approaches nearly 25,000 tons $\left(150,000 \mathrm{~m}^{3}\right)$. In this study, we discuss the process and timing of the deposition of litter from the sea surface onto a beach by large waves using images from live cameras located along the Fuji coast. Live camera images recorded over a period of 14 months from September 2007 to November 2008 were used in this study in addition to records of wave height, wave period, wind direction, wind velocity, and tide level. Analysis of these images and relevant oceanographic data showed that: (1) the floating litter on the sea surface in the nearshore area was washed up on the sandy beach by long waves caused by typhoons, (2) on the specified day the wind drifted the litter floating on the sea towards the shore, (3) the tidal change did not contribute to deposition of litter on the beach and (4) the clean up of litter was carried out by the appropriate section of the prefecture and city, and required a period in 1 to 5 months per event.
\end{abstract}

Key words: Drifting litter, live camera, washing-up of floating litter, Fuji coast.

\section{Introduction}

Along a beautiful $20 \mathrm{~km}$ stretch of the Fuji coast in Japan (Fig.1), between the Fiji and Kano river mouths, large amounts of litter are washed up on occasion by swells generated by the passage of typhoons or low pressure systems. The origin and route of this washed up litter are surmised as follows: When heavy rain caused by a typhoon falls and extreme weather in the upper and middle areas of a river catchment occurs, mountain-slope landslides occasionally result. The fallen trees from such an event flow down the river as driftwood. In addition, trash from the towns within the river catchment may also flow from the river mouth into the sea. This floating litter is carried by wind and waves and washed up on another shore further along the coast from the river mouth. This may result in beautiful coastal areas, including recreational beaches, becoming inundated with this refuse if it is not removed. Countermeasures against the accumulation of litter must therefore be considered. One such measure, the Coast Litter Disposal Promoting Law, was promulgated on July 15,2009 , in Japan. There is currently very

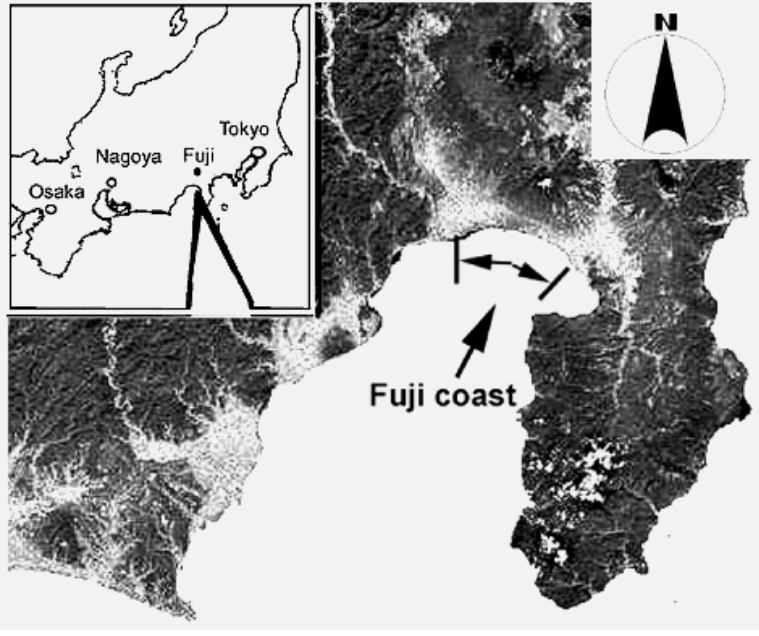

Fig. 1 Fuji coast 
little information on the timing and processes by which floating litter is washed up on the coast. An understanding of the process of litter deposition is useful in the discussion of possible countermeasures. In this study, we discuss the effects of the sea and weather conditions on litter deposition based on live camera images and records of wave height, wave period, wind direction, wind velocity, and tide

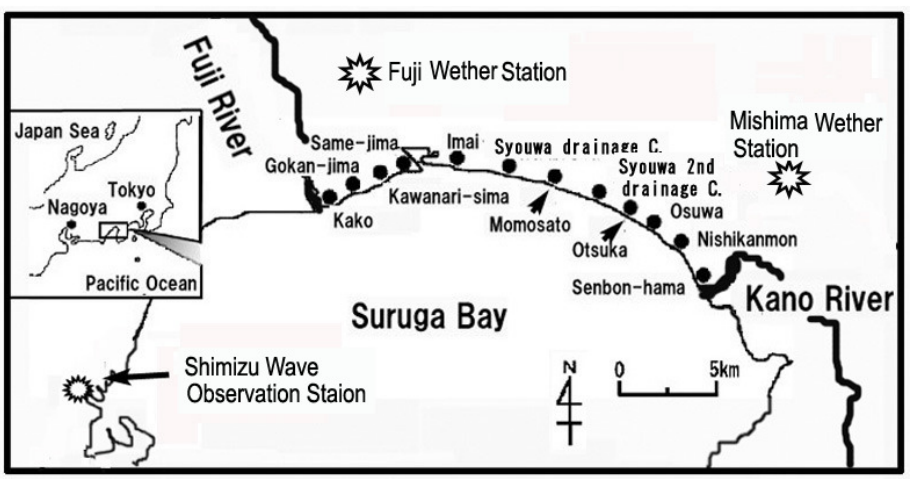

Fig .2 Locations of live cameras along the Fuji coast, as well as the wave and weather observation stations used in this study.

level.

\section{Study site}

The Fuji coast is located in the inner part of Suruga Bay, and sited between the mouths of the Fuji and Kano rivers as shown in Figs. 1 and 2. The length of the coast is about $20 \mathrm{~km}$. The shoreline slope, as measured at the intersection of the mean sea water level and the crossshore beach section, ranges from $1 / 3$ to $1 / 10$. Waves during storm events were measured at the nearby Shimizu Wave Observatory Station (Fig. 2) during 2007, and over the duration of this study can be described as follows: significant the wave height $\mathrm{H}_{1} / 3$ was $5 \mathrm{~m}$ and the wave period $T 1 / 3$ was $13.6 \mathrm{~s}$. The incident wave direction is from SW to SSW, and the angle of wave incidence to the shoreline is approximately $90^{\circ}$. The dominant direction of strong winds is SW throughout the year.

\section{Data collection}

Twelve live cameras located along the coastal dike shown in Fig. 2 are operated by the Numazu Construction Office of the Chubu Branch, Ministry of Land, Infrastructure, Transport and Tourism ${ }^{1)}$ in order to aid the preservation of the Fuji coast. The beach and wave run up conditions recorded by these cameras can be viewed on the Internet every five to eight minutes. The live camera images provide a lot of information about phenomena that are occur on

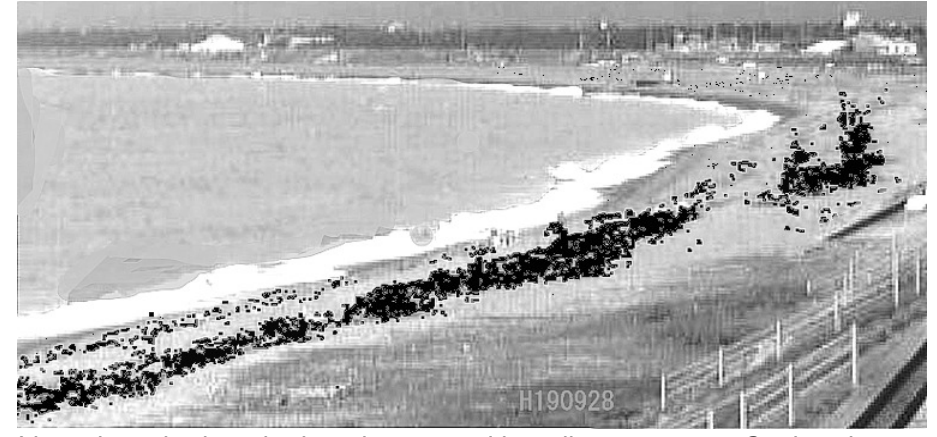

Fig. 3 Litter deposited on the beach captured by a live camera at Senbon-hama station. Image processing was performed in order to improve the recognition of litter. 
the coast. We saved these images captured from the cameras over 14 months (September 2007 to November 2008) to a personal computer in order to observe the deposition of litter. The

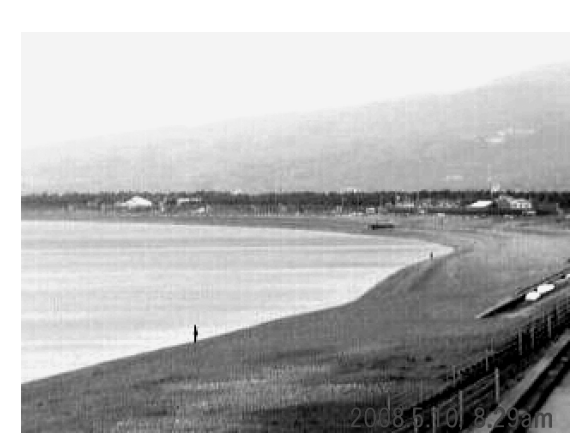

(a) May 10, 2008

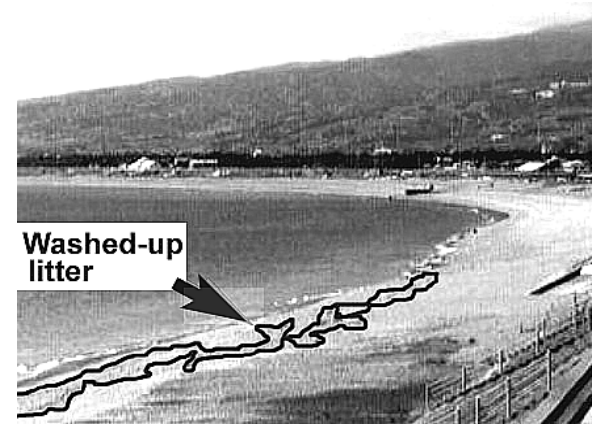

(b) May 13, 2008

Fig.4 Litter washed up on Senbon-hama beach captured by live camera. Image (b) was taken on May 13, 2008, after Typhoon No. 0802 passed far to the south of this coastline.

presence of litter can be visually assessed from these images. The litter on the beach is easily recognized after image processing with a personal computer (see Fig. 3). This image was processed to show the washed up litter in black using Adobe Photoshop Ver.6.

\subsection{Identification of washed up}

Fig. 4 shows two images captured by the live camera at Senbon-hama. While no litter was present in the image taken on May 10 (Fig. 4a), litter was washed up on May 13 (Fig. 4b).

Table 1 Existence of litter on each beach on the basis of images captured via live cameras.

\begin{tabular}{|c|c|c|c|c|c|c|c|c|c|}
\hline \multirow[b]{2}{*}{$\begin{array}{c}\text { Day } \\
\text { (May 2008) }\end{array}$} & \multirow{2}{*}{$\begin{array}{l}\text { Time of } \\
\text { live } \\
\text { camera } \\
\text { image }\end{array}$} & \multicolumn{6}{|c|}{ Live camera location } & \multicolumn{2}{|l|}{ Remarks } \\
\hline & & $\begin{array}{l}\text { Senbon- } \\
\text { hama }\end{array}$ & $\begin{array}{c}\text { Nishi- } \\
\text { kanmon }\end{array}$ & Osuwa & Otsuka & $\begin{array}{l}\text { Syowa } \\
\text { 2nd } \\
\text { drainage } \\
\text { channel }\end{array}$ & Momosato & $\begin{array}{c}\text { Typhoon, low pressure, wave } \\
\text { height and period }\end{array}$ & Precipitation \\
\hline 9 & $12: 41$ & & & & & & & & \multirow{6}{*}{$\begin{array}{l}\text { In five days } \\
\text { between } 1 \text { st to } \\
13 \text { th May, } \\
\text { precipitation of } \\
30-50 \mathrm{~mm} / \text { day }\end{array}$} \\
\hline 10 & $8: 25$ & & & $x$ & & & $x$ & & \\
\hline $\begin{array}{c}11 \\
\text { (storm) }\end{array}$ & $12: 35 \sim 39$ & & & $x$ & $\Delta$ & & & $\begin{array}{l}\text { Frontal cyclone and low pressure } \\
\text { pass in an easterly direction over } \\
\text { the sea to the south in the Izu } \\
\text { Islands. }\end{array}$ & \\
\hline 12 & $10: 15$ & & & $\Delta$ & $\Delta$ & $\triangle$ & & $\begin{array}{l}\text { Typhoon No. } 0802 \text { passes in a NW } \\
\text { direction over the southern sea. }\end{array}$ & \\
\hline 13 & $16: 37 \sim 42$ & $\triangle$ & & 0 & $\triangle$ & 0 & $\triangle$ & $\begin{array}{l}\text { Typhoon No. } 0802 \text { passes to the } \\
\text { south of Hatijyo-jima. Port of } \\
\text { Simizu: } H 1 / 3=1.5 \mathrm{~m} \text {. T1/3=16s. }\end{array}$ & \\
\hline 14 & $12: 43 \sim 44$ & O & & 0 & 0 & 0 & 0 & $\begin{array}{l}\text { Low pressure passes over the Sea } \\
\text { of Japan and southern part of the } \\
\text { main island of Japan. }\end{array}$ & \\
\hline $\begin{array}{l}\text { Note: } \\
" \mathrm{O} " \\
" \Delta " \\
" X "\end{array}$ & $\begin{array}{l}\text { considerab } \\
\text { less litter } \\
\text { no-litter } \\
\text { assesment }\end{array}$ & impo & f litte & & & & & & \\
\hline
\end{tabular}


The direction and angle of the live camera are fixed, and the live camera image is considerably affected by weather conditions such as rain and the angle of sunlight. In bad weather, the presence of litter on the beach could not be assessed using the images. Table 1 summarizes the results for the existence of litter on each beach using the images captured by six live cameras. "Circle-mark" indicates where considerable amounts of litter accumulated; "triangle-mark" indicates where less litter accumulated; "blank" indicates where litter could not be recognized in the image; and " $X$ " indicates when the assessment to the image that were captured due to bad weather conditions is impossible, in the term of May 914. Table 1 shows that litter did not accumulate until May 10 (light gray) and was clearly recognized by five of the six live cameras after May 13 (dark gray). The litter was likely washed up as a result of the strong waves impacting the Fuji coast at this time. On May 11, a frontal cyclone and low-pressure system passed in an easterly direction over the Izu Islands and sea to the south. On May 12-13, Typhoon No. 0802 passed in a northwesterly direction over the sea to the south of the Fuji coast. In addition, there was heavy rainfall (30-50 $\mathrm{mm} /$ day) in the Kano River catchment for five days between May 1-13. This rainfall likely resulted in the transport of wood from mountainous areas and anthropogenic litter from the urban areas in the catchment flow the river into Suruga Bay.

\subsection{Monthly change in the distribution of washed up litter}

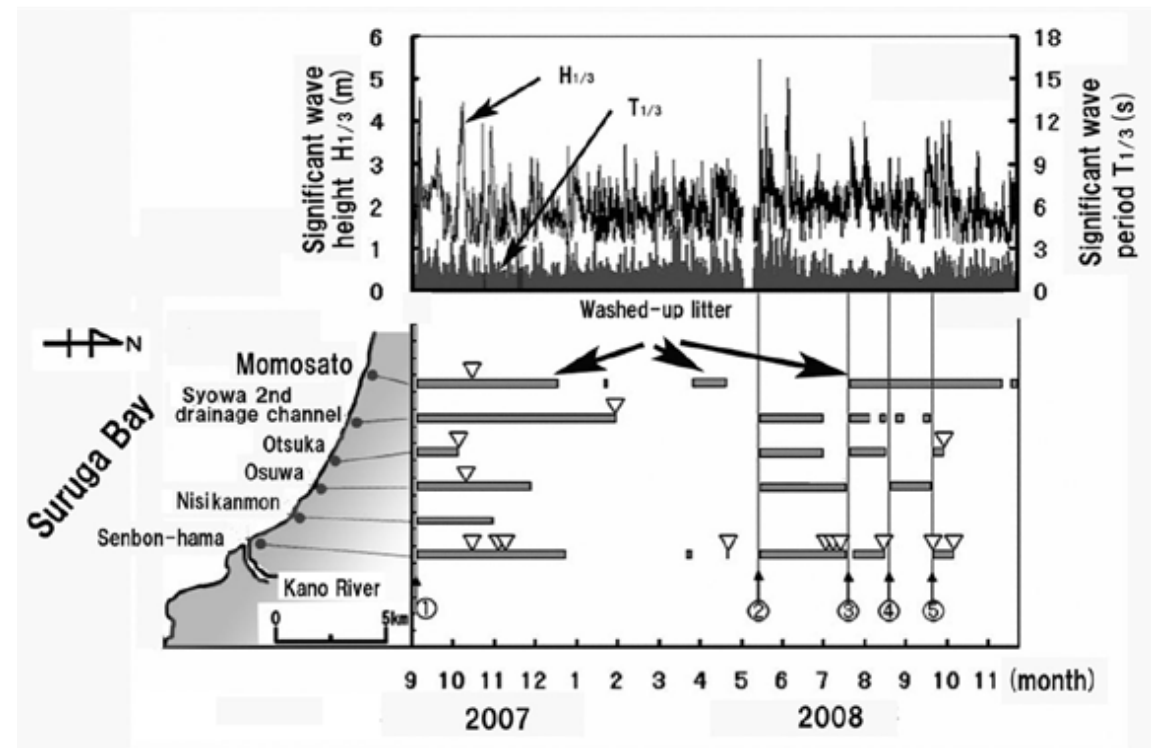

Fig 5 Time history of litter deposition captured by live cameras at six locations, and corresponding wave parameters.

The symbols in the figure are as follows:

"Inverse triangle" Indicates cleanup days.

(1)Typhoon No. 0709 struck the Izu Peninsula in Sizuoka Prefecture on September 6 2007, and moved from south to north over the main island of Japan. Rainfall of $595 \mathrm{~mm} /$ day was observed in the Kano River basin. Fuji City recorded a maximum wind velocity of $13 \mathrm{~m} / \mathrm{s}$.

(2)Typhoon No.0802 passed over the sea in the south of the Izu Peninsula.

(3)Typhoon No.0807 was generated on July 14 2008. The seasonal rain front moved slowly east and thunderstorms occurred between west and east of Japan on July 18. A large amount of washed up litter was recognized in the live camera images.

(4)Typhoon No.0811 migrated south of Hachijo-jima, and waves of $H_{1 / 3}=1.1 \mathrm{~m}$ and $T_{1 / 3}=9.0 \mathrm{~s}$ were generated.

(5)Typhoon No.0813 moved south of the main island, and waves of $H_{1 / 3}=1.9 \mathrm{~m}$ and $T_{1 / 3}=10.5 \mathrm{~s}$ were generated. 
The presence or absence of litter on the beach was assessed using live camera images captured over 14 months (September 2007 to November 2008). Six live cameras were used in this study: Senbon-hama, Nishikanmon, Osuwa, Otsuka, Syowa second drainage channel, and Momosato, near the Kano River mouth (Fig. 5). In addition, the presence of litter is shown as a horizontal bar and the times when beach clean-up work was undertaken and captured by the cameras is shown by an inverted triangle. Days when litter was concurrently recognized by different live cameras are shown by the vertical lines numbered (1) to (5). Also, times series of the significant wave height and period of incident waves are illustrated using the wave records from the Shimizu Wave Observation Station ${ }^{2}$. Vertical lines (1) and (2) coincide with an extreme wave events and indicate the beginning of litter deposition. Lines (3) to (5) indicate that the timing of litter deposition is the same across the some locations. This deposited litter photographed by the live cameras is assumed to have originated from the Kano River mouth.

In Section 5 below, we closely examine the effect of incident waves, wind speed and direction, and tidal level on litter deposition for the period May 9-17, 2008.

\section{Beach clean-up efforts}

The litter in this area was periodically cleaned-up by volunteer groups with the support of Numazu City. In addition, members of the community and elementary and junior high school students occasionally assisted in the clean-up. The inverse triangles in Fig. 5 mark the dates when persons involved in clean-up work were observed in the captured images. The cleanup work, which requires a period of 1 to 5 months per event, was conducted frequently when litter was washed up.

\section{Influence of sea and wave climates}

The records of significant wave height, period, wind speed and direction, and tidal level for May 9-17 2008 are shown in Fig. 6. The waves and tidal levels were observed by the Shimizu Wave Observation Station ${ }^{2)}$, and the wind direction and velocity were observed by the Fuji Weather Station located approximately $17 \mathrm{~km}$ northwest of the study site. The two vertical broken lines in Fig. 6 show the final day on which litter was not recognised and the day on which litter was recognised in five live camera images. The days on which litter was first recognised were the morning of May 10 and the afternoon of May 13, respectively.

The Kano River basin experienced considerable precipitation over the period of May 11-13 due to the influence of a low pressure system and Typhoon No. 0802 passing over the sea to the south. Thus, we assume that any wood in the washed-up litter was transported via the Kano River mouth to the sea by the associated floodwaters. The wind on May 13 changed direction from being westerly to a northerly between the morning and the afternoon, and it is likely that the strong winds $(7 \mathrm{~m} / \mathrm{s})$ first pushed the floating litter from the Kano River mouth offshore, and then back onshore once the wind direction changed. On May 13 (Fig. 6), the Fuji coast was impacted swells generated by this typhoon, with a peak in wave activity observed in the morning. We conclude that this strong swell washed the floating litter up on the coast 


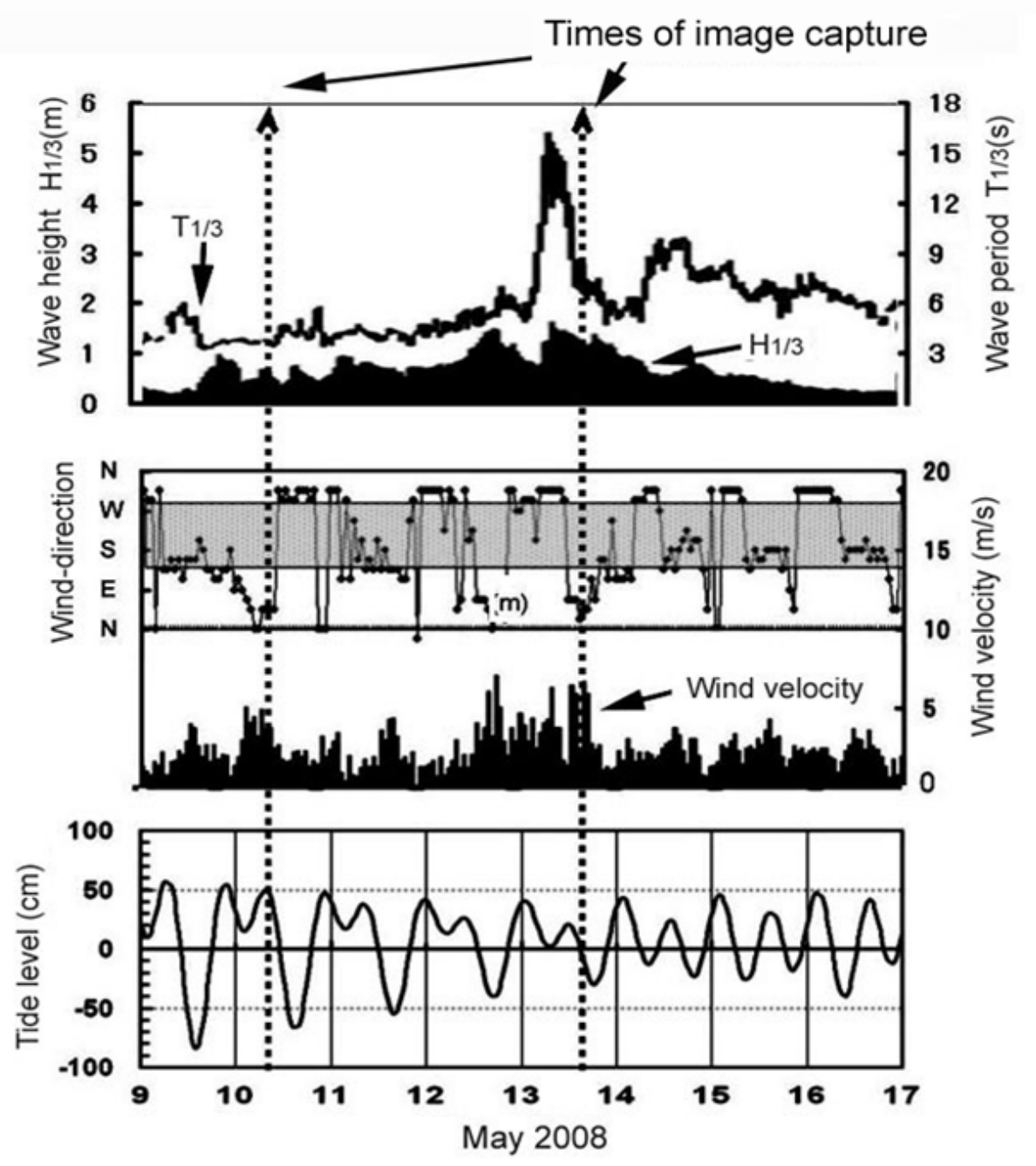

Fig. 6 Time series of wave height and period, wind velocity and direction, and water level from May 9-17, 2008.

\section{Effect of wind velocity and direction}

The wind direction was divided into 16 segments in a clockwise direction, where 1 and 17 correspond to north, 5 to east, 9 to south, and 13 to west. Time series of wind velocity and direction are illustrated in Fig. 6, and times when the wind blew from the sea towards the coast are marked in grey. These wind data were collected by the Fuji Weather Station. From this figure, we infer that when the wind blew towards the shore on May 11-12, the floating litter on the sea surface drifted towards the shore and was subsequently washed up on the coast by the strong swells.

Since there are no meteorological stations located in the immediate vicinity of the Fuji coast, we used wind data collected by the Fuji and Mishima Wind Stations. As shown in Fig. 2, the Fuji and Mishima Wind Stations ${ }^{3)}$ are located approximately $17 \mathrm{~km}$ to the northwest and $7.3 \mathrm{~km}$ to the east of the Fuji coast, respectively. To examine the effect of wind velocity and direction in this study we 
used the wind blowing distance that is defined as the product of wind velocity and the wind blowing time. The wind blowing time expresses the time in which the wind of some speeds blew and expresses the relative distance over which the wind blows the litter. The integrated wind blowing distance was calculated over the period May 8-13 using wind data measured at both the Fuji and Mishima Weather Stations.

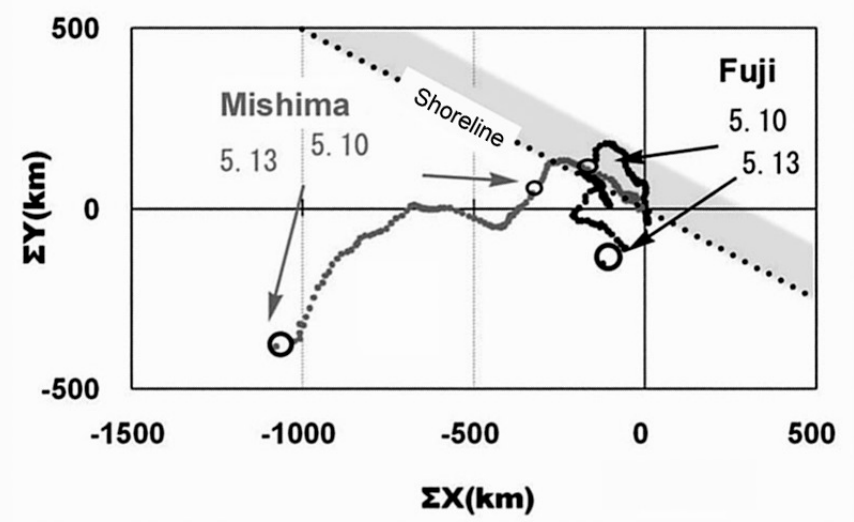

Fig.7 Relative Eulerian description of transportation of floating litter by wind.

The wind data at the two weather

stations is useful for examining how the migration route of the typhoon or low pressure influences the drift-route of the floating litter. The integrated wind blowing distance results are shown in Fig. 7 in an Eulerian format with May 8 as the origin. The small circle indicates 08:00 May 10 and the large circle 16:00 May 13. The approximate position of the shoreline in the study area is illustrated by the dotted line. This figure shows the relative effect of the wind on the floating litter. Using the data from the Fuji Weather Station, the integrated wind blowing distance moves in a NE direction (upper right in Fig.7) from May 8 (origin) to May 10. In the period of May 10-13, the litter moves parallel to the shoreline. For the Mishima wind data, the integrated wind blowing distance was similar to that obtained for Fuji until May 10, with movement from the origin to the NE direction (upper right in this figure). However, after May 10 the litter would have likely drifted offshore.

The integrated wind blowing distance determined using the data from two wind stations is similar until May 10. For May 10-13, the integrated wind blowing distance using data from the Fuji wind station shows that the floating litter likely drifts from the Kano River mouth to Senbon-hama, before moving parallel to the shoreline close to shore. However, the data from Mishima does not corroborate this finding. Thus, the use of the Fuji Wind Station data indicates the drift of the floating litter from the sea towards the shore.

However, it is important that the effect of wind on the floating litter be examined using various data sources in cases of high waves or storm surges associated with typhoons directly impacting the Fuji coast.

\section{Effect of Tides on Washing up Litter Deposition}

The tidal level during the event of interest ranged between -70 and $+50 \mathrm{~cm}$ relative to the mean sea level (Fig. 6). An abnormal water level change due to the storm surge in response to Typhoon No. 0802 was not identified from the tidal level changes according to the lunar cycle. The tidal level decreased gradually from 00:00 on May 13 to the time when the image was captured (16:37-16:42 pm), and in this period the incident wave period peaked (swell waves) and returned to normal. Consequently, the effect of water level variation on the deposition of litter is not discussed quantitatively or in detail for the period examined in this study. 


\section{Conclusions}

The results of this study on the process and timing of the deposition of litter on the Fuji coast can be summarized as follows:

1) The integrated wind blowing distance was calculated for the period of May 8-13, 2008, using wind data obtained by the Fuji Weather Station. The results indicate that the wind likely pushes the floating litter towards the shore. Litter floating on the sea surface is therefore considerably affected by the prevailing wind speed and direction.

2) The integrated wind blowing distance calculated using data from the Mishima Weather Station located approximately $7.3 \mathrm{~km}$ to the east of the Fuji coast, does not adequately explain the drift of litter on the sea during the period of strong swells from May 10-13.

3) The passage of Typhoon No. 0802 over the Pacific Ocean south of Suruga Bay produced strong swells, in the order of $\mathrm{H} 1 / 3=1.5 \mathrm{~m}$ and $\mathrm{T} 1 / 3=16 \mathrm{~s}$, on the Fuji coast. We consider that this large swell washed the litter floating near the shore onto the beach.

4) The litter clean-up efforts require between 1-5 months per event under current cleaning practices.

5) Tidal level variations did not influence the deposition of litter in the period examined in this study.

\section{References}

1) Live camera website at the Numazu Construction Office, Chubu Branch, the Ministry of Land, Infrastructure, Transport and Tourism, Japan: https:/www2.cbr.mlit.go.jp/numazu/ cgi-

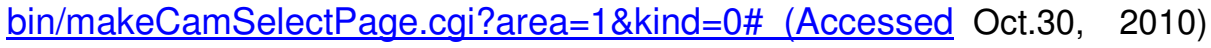

2) NOWPHAS (Nationwide Ocean Wave information network for Ports and HArbourS) website: http://nowphas.mlit.go.jp/eng.htm (Accessed Oct.31, 2010)।

3) Japan Meteorological Agency website: Data on tide, Wind direction and velocity, http://www.jma.go.jp/jma/indexe.html (Accessed Oct.29, 2010) 